Original paper

\title{
Induction of synthesis of matrix metalloproteinases by interleukin-6; evidence for hepatic regeneration following hemi-hepatectomy
}

\author{
Thamer Alghamdi', Ihab Shafek Atta ${ }^{2,3}$, Mohamed El-Refaei ${ }^{4}$ \\ 'Surgery Department, Albaha Faculty of Medicine, Saudi Arabia \\ 2Pathology Department, Faculty of Medicine, Al-Azhar University, Assuit, Egypt \\ ${ }^{3}$ Pathology Department, Faculty of Medicine, Albaha University, Saudi Arabia \\ ${ }^{4}$ Biochemistry Department, Albaha University, Faculty of Medicine, Saudi Arabia
}

\begin{abstract}
Aim of the study: Interleukin-6 (IL-6) can play a role in hepatic regeneration through many mechanisms, one of which is the induction of synthesis of matrix metalloproteinases (MMPs). The aim of the study is to focus on the significance and role of MMPs in the regenerative process to reveal the correlation between IL- 6 and MMPs in rats following partial hepatectomy.

Material and methods: Following hemi-hepatectomy, eighty male rats were divided into a control group and a group treated with IL-6 $35 \mu \mathrm{g} / 100 \mathrm{gm}$ body weight according to a lethality study. The blood samples were drawn from all animal groups for MMP-9 serum level assessment. For the quantitative determination of MMP-9 an enzyme-linked immunosorbent assay (ELISA) was used (Cytoimmune Science Inc., MD) through the quantitative sandwich immunosorbent assay technique. A monoclonal antibody for MMP-9 was pre-coated onto microplate standards. After washing away the unbound substances, an enzyme-linked polyclonal antibody specific for cytokine was added to the wells and color developed in proportion to the amount of total cytokine (pro and/or active) bound in the initial step. The color development was stopped and the intensity of the color was measured. Results: The liver regeneration rate (\%) was significantly higher in the group of rats treated with IL-6 (median value was $49.55 \%$ vs. $33.20 \%), p<0.001$. The MMPs' serum level was significantly higher in the group of rats with resection and treatment (median value was 8.01 ).

Conclusions: These results give evidence for the vital role of MMPs in the process of hepatic regeneration, the level of which, in turn, has a close relationship with the level of IL-6. MMPs have diverse effects in promoting angiogenesis, remodeling of extracellular matrix and endothelial cell proliferation.
\end{abstract}

Key words: interleukin-6, metalloproteinases, hemi-hepatectomy, rats, liver regeneration.

Address for correspondence:

Dr. Thamer Alghamdi, Surgery Department, Albaha Faculty of Medicine, the main Faculty campus, Al-Aqiq, 1988,

Saudi Arabia, e-mail: tthaker@bu.edu.sa

\section{Introduction}

The most important hepatic reaction is its response to regeneration following injury $[1,2]$ and it is apparent from previous experiments that soluble extrahepatic factors offer a stimulus for the regenerative process [3]. Within the first two hours after hepatectomy, the levels of interleukin-6 (IL-6) and tumor necrosis factor $\alpha$ (TNF- $\alpha$ ) increased in the liver vein, associated with activation of Kupffer cells by gut-derived factors such as lipopolysaccharide [4] resulting in TNF- $\alpha$-dependent secretion of IL-6 [5]. In addition, it has been found that IL-6 knockout in mice resulted in an impaired hepatic regenerative process [6]. Furthermore, the number of progenitor cells included in the regenerative process is reduced when IL-6 signaling is delayed or stopped [7]. These experimental data pointed to an important role of IL-6 in liver regeneration. 
A family of zinc-dependent endopeptidases is known as matrix metalloproteinases (MMPs), which act in harmony with their inhibitors, called tissue inhibitors of metalloproteinases (TIMPs) to organize the degree and rate of extracellular matrix degradation $[8,9]$. This action is evident in many events including embryologic development, growth and metastasis of tumors, tissue regeneration, and ovulation [10-12]. Remodeling of the extracellular matrix (ECM) by MMPs is decisive for angiogenesis from pre-existing vessels $[13,14]$.

Matrix metalloproteinases are synthesized and secreted as inactive proenzymes that are activated by a variety of proteinases such as plasmin $[15,16]$. For instance, pro-MMP-2 is activated by membrane type 1 - MMP and plasmin $[17,18]$. In addition, pro-MMP-9 is activated by MMP-3 and plasmin [19, 20]. Because matrix turnover is known to be tightly regulated, activation of pro-MMPs to active MMPs is firmly controlled by complex formation with tissue inhibitors of MMPs (TIMPs). Several studies have shown that several MMP members are expressed in stellate cells or hepatocytes $[21,22]$. In addition, dysregulated expression of MMPs has been revealed in both hepatoma and fibrotic liver disease [23, 24].

The aim of the present study is to focus on the significance and role of MMPs in the regenerative process. In addition, the aim is to reveal the correlation between IL-6 and MMPs in rats following partial hepatectomy.

\section{Material and methods}

An 80 adult male Sprague-Dawley rats weighing about 200-230 g were obtained from the animal residence for scientific studies, King Abdulaziz University (Jeddah, Kingdom of Saudi Arabia). The animals were housed in a pathogen-free environment in the animal residence of the Faculty of Medicine, Albaha University, Kingdom of Saudi Arabia, in a 12-h light-dark cycle with meals and water obtainable ad libitum. 70\% partial hepatectomy was performed on 40 rats. All animal experiments were performed according to the Guide for the Care and Use of Laboratory Animals published by the National Institutes of Health, USA. All surgical procedures were performed under inhalation anaesthesia.

\section{Interleukin-6 lethality study on rats}

The male rats were randomly assigned to 7 groups of 5 rats each. They were treated with diverse doses in the range $20-80 \mu \mathrm{g} / 100 \mathrm{~g}$ of IL- 6 and the number of surviving rats was recorded daily. The starting dose was of $80 \mu \mathrm{g} / 100 \mathrm{~g}$ (for the first group), which decreased by $10 \mu \mathrm{g} / 100 \mathrm{~g}$ for each group until reaching $20 \mu \mathrm{g} / 100 \mathrm{~g}$ for the last group. The dose that caused deaths among all groups was recorded and the finding revealed that a dose of more than $35 \mu \mathrm{g} / 100 \mathrm{~g}$ can cause deaths among the rats and the number of deaths was directly proportional to the dose level, i.e. the higher the dose, the higher the death rate. The surviving rats were recorded This procedure was continued for 30 days. The rats were subjected to the experiments following the ethical standards.

\section{Experimental design}

Eighty male rats were classified into two equal groups ( $n=40$ rats) to undergo $70 \%$ partial hepatectomy. Group 1 was the non-treated group and group 2 was the treated group: 40 rats treated with $35 \mu \mathrm{g} / 100 \mathrm{gm}$ body weight according to lethality study (dose and time dependent) [25]. The treated group was treated intravenously daily for three days, starting on the day of surgery (day zero) and sacrification was done on the fourth day. Towards the end of the treatment period, the liver was removed, weighed. and bisected longitudinally for further histopathological and immunohistochemistry studies.

\section{Liver weight and regeneration rate}

The preoperative total liver weight was calculated from the resected liver weight. Postoperative total liver weight was measured at sacrifice [26]. The change in liver weight was evaluated as the hepatic regeneration rate (RR). RR is defined as (liver weight per $100 \mathrm{~g}$ of body weight at sacrifice/preoperative projected liver weight per $100 \mathrm{~g}$ of body weight $) \times 100: \mathrm{RR}=(\mathrm{LWm} / 100 \mathrm{~g}$ body weight $[\mathrm{BW}]) \mathrm{sac} /(\mathrm{LWp} / 100 \mathrm{~g} \mathrm{BW})$ pre $\times 100$. LWm is the measured liver weight at sacrifice; LWp is the preoperative projected liver weight.

\section{Determination of serum levels of matrix metalloproteinase (MMP-9)}

Blood samples were drawn from all animal groups for MMP-9 serum level assessment. The samples were transported to plastic tubes free of anticoagulant and were left to clot. Later, the samples were centrifuged to obtain serum, which was stored at $-70^{\circ} \mathrm{C}$. For the quantitative determination of MMP-9, competitive enzyme-linked immunosorbent assay (ELISA) (Cytoimmune Science Inc., MD) was used. For each sample, $100 \mu \mathrm{l}$ of serum sample was added to the designated wells. This assay employs the quantitative sandwich immunosorbent assay technique. A monoclonal an- 
tibody specific for MMP-9 was pre-coated onto a microplate. Standards and samples were pipetted into the wells and cytokine bound by the immobilized antibody. After washing away the unbound substances, an enzyme-linked polyclonal antibody specific for cytokine was added to the wells. Following a wash to remove any unbound antibody, an enzyme reagent and a substrate solution were added to the wells and color developed in proportion to the amount of total cytokine (pro and/or active) bound in the initial step. The color development was stopped and the intensity of the color was measured [27].

The Mann-Whitney $U$-test was used to estimate the regenerative rate between the treated and non-treated group. The $P$-value is considered significant at $\leq 0.05$.

\section{Results}

The liver regeneration rate (\%) was significantly higher in the group of rats treated with IL-6 compared to those not treated (median values was $49.55 \%$ vs. $33.20 \%), p<0.001$ (Table 1). The metalloproteinase serum level (MMP-9) was significantly higher in the group of rats with resection and treatment compared to those with $70 \%$ liver resection (median values were 8.01 and 6.17, respectively), $p<0.001$ (Table 2). The histological and proliferative signs of hepatic regeneration were found more marked in the treated than in the non-treated group.

\section{Discussion}

In the present study, the liver regeneration rate was significantly higher in the group of rats treated with IL-6 compared to those not treated (median values was $49.55 \%$ vs. $33.20 \%$ ), $p<0.001$. The metalloproteinase serum level (MMP-9) was significantly higher in the group of rats with resection and treatment compared to those with $70 \%$ liver resection (median values were 8.01 and 6.17, respectively), $p<0.001$.

Regarding the rate of regeneration, our results are compatible with those of Andersen et al. [26], who found that $70 \%$ partial hepatectomy in rats induced by IL-6 showed a rapid regenerative response with a maximum rate on the fourth day post-operatively. Also, it coincides with many studies which assessed the role of IL-6 in the process of liver regeneration [28-31].

It has become progressively clearer that liver regeneration is dependent on angiogenesis. The apoptosis and endothelial cell proliferation that are an adjunct to hepatic regeneration, for instance, can be adjusted during the treatment by angiogenic agents [32]. Matrix metalloproteinases are a vital requisite in the normal
Table 1. Comparison of liver regeneration rate between group of rats with matrix metalloproteinase-9 (MMP-9) treatment and those without treatment

\begin{tabular}{lcc}
\hline $\begin{array}{l}\text { Regeneration } \\
\text { rate (\%) }\end{array}$ & $\begin{array}{c}\text { Without IL treatment } \\
n=20\end{array}$ & $\begin{array}{c}\text { With IL treatment } \\
n=20\end{array}$ \\
\hline Median & 33.20 & 49.55 \\
\hline IQR & $30.6-33.9$ & $47.1-51.2$ \\
\hline Mean rank & 11.5 & 29.50 \\
\hline$p$-value* & \multicolumn{3}{c}{$<0.001$} \\
\hline
\end{tabular}

IQR - inter-quartile range, *Mann-Whitney (U)-test

Table 2. Comparison of metalloproteinase serum level (MMP-9) between group of $70 \%$ liver resection and group of resection and treatment

\begin{tabular}{lcc}
\hline MMP-9 serum & \multicolumn{2}{c}{ Groups } \\
\cline { 2 - 3 } & $\begin{array}{c}\text { 70\% liver resection } \\
n=20\end{array}$ & $\begin{array}{c}\text { Resected and treated } \\
n=20\end{array}$ \\
\hline Median & 6.17 & 8.01 \\
\hline IQR & $5.96-6.30$ & $7.91-8.12$ \\
\hline Mean rank & 10.5 & 30.5 \\
\hline$p$-value* & \multicolumn{3}{c}{$<0.001$} \\
\hline
\end{tabular}

IQR - inter-quartile range, *Mann-Whitney U-test

events of the hepatic regenerative course. This supposition was based on the reality that MMPs are dynamic in both angiogenesis and extracellular matrix remodeling. Roy et al. offered evidence for the role of MMPs in liver regeneration and revealed their expression in the urine following partial hepatectomy and that their outlines have a positive correlation with the regenerative staging process [8], and urinary MMP expression showed a degree of modification upon administration of the angiogenesis agents [33]. Also, further evidence comes from administration of a broad-spectrum MMP inhibitor in rats following partial hepatectomy, in which the hepatic regenerative process was inhibited. This evidence indicates that MMPs are imperative for hepatic regeneration following partial hepatectomy.

Matrix metalloproteinases promote liver regeneration owing to their direct effect on remodeling of extracellular matrix, a procedure that is essential to hepatic regeneration [34-36]. On the other hand, MMPs promote the regenerative course by an indirect mechanism, during their angiogenetic effects by aiding in the process of endothelial migration during the degraded extracellular matrix stage. Additionally, MMPs induce the extracellular matrix to secrete pro-endothelial growth factors [36]. Thus, MMP inhibitors may arrest the process of hepatic regeneration via inhibiting the remodeling of the extracellular matrix or cessation of the capillary configuration [37]. Also, it has been found that inhibition of MMPs by their inhibitors will 
give rise to an increased level and activation of IL-6, which means that both MMPs and IL-6 have a concomitant effect on each other and exert an effect on liver regeneration [38]. Kim et al. recommended that hepatic matrix remodeling might be a prerequisite procedure for proliferation of hepatocytes in the process of regenerating liver following injury or partial hepatectomy [34].

The rate of hepatic regeneration in the treated group was higher than in the non-treated group. This is documented by evidence from histopathological and immunohistochemical studies, which is in agreement with many studies $[25,39,40]$.

\section{Conclusions}

These results in association with previous studies provide evidence for the vital role of MMPs in the process of hepatic regeneration, the level of which, in turn, has a close relation with the level of IL-6. MMPs have diverse effects in promoting angiogenesis, remodeling of extracellular matrix and endothelial cell proliferation.

\section{Disclosure}

The authors report no conflict of interest.

\section{References}

1. Michalopoulos GK, DeFrances MC. Liver regeneration. Science 1997; 276: 60-66.

2. Michalopoulos GK. Liver regeneration after partial hepatectomy: critical analysis of mechanistic dilemmas. Am J Pathol 2010; 176: 2-13.

3. Fisher B, Szuch P, Levine M, Fisher ER. A portal blood factor as the humoral agent in liver regeneration. Science 1971; 171: 575-577.

4. Trautwein C, Rakemann T, Niehof M, et al. Acute-phase response factor, increased binding, and target gene transcription during liver regeneration. Gastroenterology 1996; 110: 18541862 .

5. Taub R. Liver regeneration: from myth to mechanism. Nat Rev Mol Cell Biol 2004; 5: 836-847.

6. Cressman DE, Greenbaum LE, DeAngelis RA, et al. Liver failure and defective hepatocyte regeneration in interleukin-6-deficient mice. Science 1996; 274: 1379-1383.

7. Yeoh GCT, Ernst M, Rose-John S, et al. Opposing roles of gp130-mediated STAT-3 and ERK-1/2 signaling in liver progenitor cell migration and proliferation. Hepatology 2007; 45: 486-494.

8. Roy R, Zhang B, Moses MA. Making the cut: protease-mediated regulation of angiogenesis. Exp Cell Res 2005; 312: 608-622.

9. Fernandez CA, Butterfield C, Jackson G, Moses MA. Structural and functional uncoupling of the enzymatic and angiogenic inhibitory activities of tissue inhibitor of metalloproteinase-2 (TIMP-2): loop 6 is a novel angiogenesis inhibitor. J Biol Chem 2003; 278: 40989-40995.
10. Greene AK, Puder M, Roy R, et al. Urinary matrix metalloproteinases and their endogenous inhibitors predict hepatic regeneration after murine partial hepatectomy. Transplantation 2004; 78: 1139-1144.

11. Moses MA. The regulation of neovascularization of matrix metalloproteinases and their inhibitors. Stem Cells 1997; 15: 180-189.

12. Folkman J. Angiogenesis. In: Braunwald E, Fauci A, Isselbacher KJ, et al. (eds.). Harrison's Textbook of Internal Medicine. McGraw Hill, New York 2001; 517.

13. Moses MA, Sudhalter J, Langer R. Identification of an inhibitor of neovascularization from cartilage. Science 1990; 248: 14081410.

14. Murphy AN, Unsworth EJ, Stetler-Stevenson WG. Tissue inhibitor of metalloproteinases-2 inhibits bFGF-induced human microvascular endothelial cell proliferation. J Cell Physiol 1993; 157: 351-358.

15. Baramova EN, Bajou K, Remacle A, et al. Involvement of PA/ plasmin system in the processing of pro-MMP-9 and in the second step of pro-MMP-2 activation. FEBS Lett 1997; 405: 157162 .

16. Fridman R, Toth M, Pena D, Mobashery S. Activation of progelatinase B (MMP-9) by gelatinase A (MMP-2). Cancer Res 1995; 55: 2548-2555.

17. Ogata Y, Enghild JJ, Nagase H. Matrix metalloproteinase 3 (stromelysin) activates the precursor for the human matrix metalloproteinase 9. J Biol Chem 1992; 267: 3581-3584.

18. Milani S, Herbst H, Schuppan D, et al. Differential expression of matrix-metalloproteinase- 1 and-2 genes in normal and fibrotic human liver. Am J Pathol 1994; 144: 528-537.

19. Takahara T, Furui K, Yata Y, et al. Dual expression of matrix metalloproteinase-2 and membrane-type 1-matrix metalloproteinase in fibrotic human livers. Hepatology 1997; 26: 15211529.

20. Geisler S, Lichtinghagen R, Boker KH, Veh RW. Differential distribution of five members of the matrix metalloproteinase family and one inhibitor (TIMP-1) in human liver and skin. Cell Tissue Res 1997; 289: 173-183.

21. Lichtinghagen R, Helmbrecht T, Arndt B, Boker KH. Expression pattern of matrix metalloproteinases in human liver. Eur J Clin Chem Clin Biochem 1995; 33: 65-71.

22. Iredale JP, Murphy G, Hembry RM, et al. Human hepatic lipocytes synthesize tissue inhibitor of metalloproteinases-1. Implications for regulation of matrix degradation in liver. J Clin Invest 1992; 90: 282-287.

23. Herbst H, Wege T, Milani S, et al. Tissue inhibitor of metalloproteinase-1 and -2 RNA expression in rat and human liver fibrosis. Am J Pathol 1997; 150: 1647-1659.

24. Iredale JP. Tissue inhibitors of metalloproteinases in liver fibrosis. Int J Biochem Cell Biol 1997; 29: 43-54.

25. Al-Ghamdi TH, Atta IS, El-Refaei M. Role of interleukin 6 in liver cell regeneration after hemi-hepatectomy, correlation with liver enzymes and flow cytometric study. Clin Exp Hepatol 2020; 6: 42-48.

26. Andersen KJ, Knudsen AR, Kannerup AS, et al. The natural history of liver regeneration in rats: description of an animal model for liver regeneration studies. Int J Surg 2013; 11: 903e908.

27. Blindenbacher A, Wang X, Langer I, et al. Interleukin 6 is important for survival after partial hepatectomy in mice. Hepatology 2003; 38: 674-682.

28. Ren X, Hogaboam C, Carpenter A, Colletti L. Stem cell factor restores hepatocyte proliferation in IL-6 knockout mice following 70\% hepatectomy. J Clin Invest 2003; 112: 1407-1418. 
29. Selzner N, Selzner M, Tian Y, et al. Cold ischemia decreases liver regeneration after partial liver transplantation in the rat: A TNF-alpha/IL-6-dependent mechanism. Hepatology 2002; 36: 812-818.

30. Sun Z, Klein AS, Radaeva S, et al. In vitro interleukin-6 treatment prevents mortality associated with fatty liver transplants in rats. Gastroenterology 2003; 125: 202-215.

31. Aref S, Salama O, Shamaa S, et al. Angiogenesis factor pattern differs in acute lymphoblastic leukemia and chronic lymphocytic leukemia. Hematology 2007; 12: 319-324.

32. Greene AK, Wiener S, Puder M, et al. Endothelial-directed hepatic regeneration after partial hepatectomy. Ann Surg 2003; 237: 530-535.

33. Haruyama T, Ajioka I, Akaike T, Watanabe Y. Regulation and significance of hepatocytederived matrix metalloproteinases in liver remodeling. Biochem Biophys Res Commun 2000; 272: 681-686.

34. Kim TH, Mars WM, Stolz DB, Michalopoulos GK. Expression and activation of pro-MMP-2 and pro-MMP-9 during rat liver regeneration. Hepatology 2000; 31: 75-82.

35. Knittel T, Mehde M, Grundmann A, et al. Expression of matrix metalloproteinases and their inhibitors during hepatic tissue repair in the rat. Histochem Cell Biol 2000; 113: 443-453.

36. Rundhaug JE. Matrix metalloproteinases, angiogenesis, and cancer. Commentary re: AC Lockhart et al., Reduction of wound angiogenesis in patients treated with BMS-275291, a broad spectrum matrix metalloproteinase inhibitor. Clin Cancer Res, 9: 00-00, 2003. Clin Cancer Res 2003; 9: 551-554.

37. Alwayn IP, Verbesey JE, Kim S, et al. A critical role for matrix metalloproteinases in liver regeneration. J Surg Res 2008; 145 : 192-198.

38. Alwayn IP, Andersson C, Lee S, et al. Inhibition of matrix metalloproteinases increases PPAR-alpha and IL-6 and prevents dietary-induced hepatic steatosis and injury in a murine model. Am J Physiol Gastrointest Liver Physiol 2006; 291: G1011-9.

39. Camargo CA Jr, Madden JF, Gao W, et al. Interleukin-6 protects liver against warm ischemia/reperfusion injury and promotes hepatocyte proliferation in the rodent. Hepatology 1997; 26: 1513-1520.

40. Hong F, Radaeva S, Pan HN, et al. Interleukin 6 alleviates hepatic steatosis and ischemia/reperfusion injury in mice with fatty liver disease. Hepatology 2004; 40: 933-941. 